\title{
Evaluation of the Target Inhalation Mode (TIM) Breathing Maneuver in Simulated Nebulizer Therapy in Patients with Cystic Fibrosis
}

\author{
John Denyer, B.Sc., Ivan Prince, M.Sc., Emma Dixon, B.Sc., ${ }^{1}$ Penny Agent, B.Sc., ${ }^{2}$ \\ Jennifer Pryor, Ph.D., ${ }^{2}$ and Margaret Hodson, M.D.?
}

\begin{abstract}
Background: Adaptive Aerosol Delivery (AAD) systems provide efficient drug delivery and improved lung deposition over conventional nebulizers by combining real-time analyses of patient breathing patterns and precisely timed aerosol delivery. Delivery and deposition are further enhanced by breathing techniques involving slow, deep inhalations.

Methods: This exploratory study assessed the acceptability of slow, deep inhalations in 20 patients with cystic fibrosis (CF) during up to eight simulated nebulizer treatments with the I-neb AAD System. The breathing maneuver, Target Inhalation Mode (TIM) breathing, involved the lengthening of the patient's inhalation time over successive breaths with guidance from auditory and tactile (vibratory) feedback from the device.

Results: At the end of the first treatment, most patients felt that the instructions were easy to understand $(90 \%)$ and that the vibratory feedback was pleasant (65\%). Half of the patients found the procedure to be comfortable. At the end of the final treatment, most patients felt that the breathing maneuver was easy to understand $(90 \%)$ and use $(80 \%)$, but that the duration of the breath was too long $(100 \%)$. Logged data revealed that $90 \%$ of patients were able to comply with the breathing maneuver. The two patients unable to comply had a forced vital capacity of $<1.75 \mathrm{~L}$. The average treatment time decreased from 288.4 to $141.6 \mathrm{sec}$ during the first and final treatments, respectively.

Conclusions: This study provides preliminary evidence of the acceptability of the TIM breathing maneuver in patients with $\mathrm{CF}$ and their ability to perform repeated TIM breathing during simulated nebulizer therapy with the I-neb AAD System.
\end{abstract}

Key words: cystic fibrosis, inhalation, I-neb Adaptive Aerosol Delivery System, target inhalation mode, TIM, Adaptive Aerosol Delivery, AAD

\section{Introduction}

C YSTIC FIBROsIs (CF) is the most common lethal autosomal recessive disorder in Caucasians. ${ }^{(1)}$ The medical treatment of CF involves multiple inhaled therapies to manage associated pulmonary complications, the primary source of morbidity and mortality in $\mathrm{CF}^{(2)}$ Despite the fact that nebulized drug therapy in CF may result in increased survival, improved lung function, fewer exacerbations, and minimal systemic effects and adverse events, variability in aerosol delivery, lung deposition, and clinical response is common. ${ }^{(3-11)}$ In addition, the large amount of time required to administer inhaled therapies, as well as the specific precautions that must be taken to minimize contamination of room air and caregiver exposure, may pose a challenge to adherence with treatment and compliance with proper device use. ${ }^{(12-15)}$ Thus, the choice of aerosol delivery system is an important consideration when prescribing nebulized therapies for patients with CF.

More than $60 \%$ of the drug delivered by conventional nebulizers is wasted to the environment. ${ }^{(16)}$ Furthermore, aerosol lung deposition with conventional nebulizers is highly dependent on the pulmonary morphology and ventilatory pattern of the patient, which may vary considerably

\footnotetext{
${ }^{1}$ Philips Respironics, Respiratory Drug Delivery (UK) Ltd, Chichester, United Kingdom.

${ }^{2}$ Cystic Fibrosis Department, Royal Brompton Hospital, London, United Kingdom.
} 
among those with pulmonary deficits. ${ }^{(9,17,18)}$ The Adaptive Aerosol Delivery (AAD; Philips Respironics, Respiratory Drug Delivery (UK) Ltd, Chichester, UK) technology was designed to improve upon conventional nebulizer systems by adapting aerosol delivery to the individual patient, based on the patient's breathing pattern. ${ }^{(19-21)}$

The first- and second-generation AAD Systems-HaloLite and Prodose-have been successfully used in clinical studies involving patients with $\mathrm{CF}$, and have been associated with more efficient drug delivery and greater patient preference compared with conventional nebulizers. ${ }^{(22,23)}$ The design of the third-generation I-neb AAD System is based on a vibrating mesh technology. ${ }^{(21)}$ The I-neb AAD System has been designed to deliver aerosol with two different breathing pattern algorithms, the Tidal Breathing Mode (TBM) and the Target Inhalation Mode (TIM). ${ }^{(24)}$ During TBM, the patient inhales spontaneously during tidal breathing and aerosol is pulsed during $50-80 \%$ of the inspiration. The duration of the aerosol pulse is dependent on the patient's inhalation time and tidal volume. During TIM the patient is guided to perform slow and deep inhalations of up to a 9-sec duration and with aerosol pulsed up to $7 \mathrm{sec}$, leaving $2 \mathrm{sec}$ for aerosol deposition in the lung. The duration of the inhalation is individualized to each patient, and with each breath the patient is coached to extend the inhalation via a vibratory feedback through the mouthpiece. Potential benefits of the use of the TIM breathing maneuver include improved aero- sol delivery and lung deposition, shorter treatment times, and greater patient acceptability and ease of use. ${ }^{(25,26)}$ The primary objective of the current study was to assess the acceptability of the TIM breathing maneuver in patients with CF during simulated nebulizer treatment with the I-neb AAD System.

\section{Materials and Methods}

This study was conducted in England with the approval of the Royal Brompton and Harefield NHS Trust \& National Heart \& Lung Institute Ethics Committee (Royal Brompton \& Harefield NHS Trust Hospital, London, UK) and in accordance with the ethical principles set forth in the Declaration of Helsinki. Patients provided written informed consent prior to participation in the study after considering their participation for at least $24 \mathrm{~h}$.

\section{Study design and patients}

This was a single-center, open-label, exploratory study conducted during a single clinic visit. Male and female patients with CF were identified by the investigator and invited to participate in the study. The diagnosis of CF was determined on the basis of sweat test or genotype analysis. Patients aged $\geq 18$ years with a forced expiratory volume in $1 \mathrm{sec}\left(\mathrm{FEV}_{1}\right)$ of $30-75 \%$ of predicted normal were eligible for the study. ${ }^{(27)}$ Patients with a history of significant exacer-

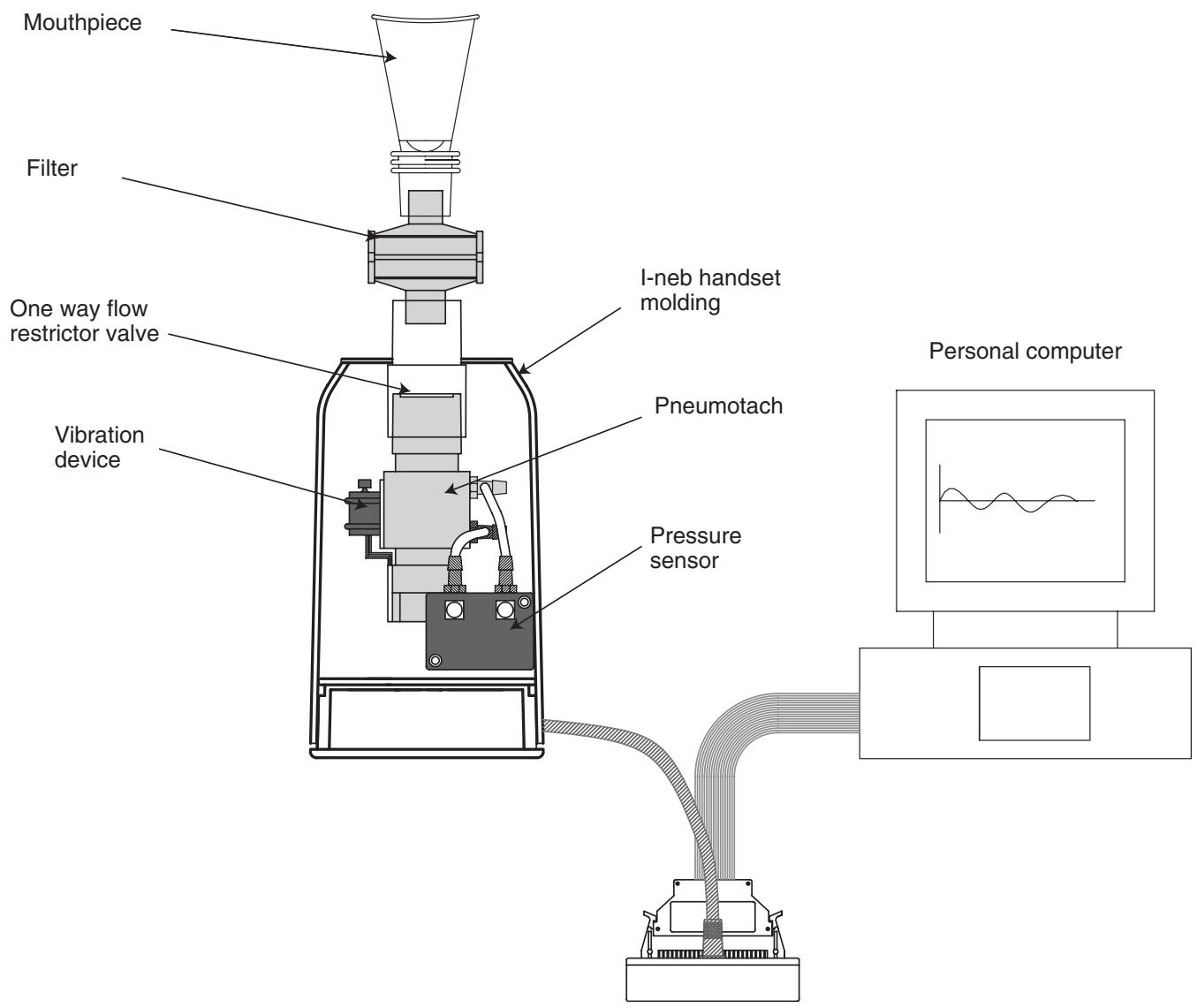

FIG. 1. The figure shows the study equipment, which consisted of a customized I-neb AAD System connected to a personal computer operating the I-neb AAD System software. A flow restrictor, a pneumotach, and a vibration device had been built into the customized I-neb AAD System handset. 


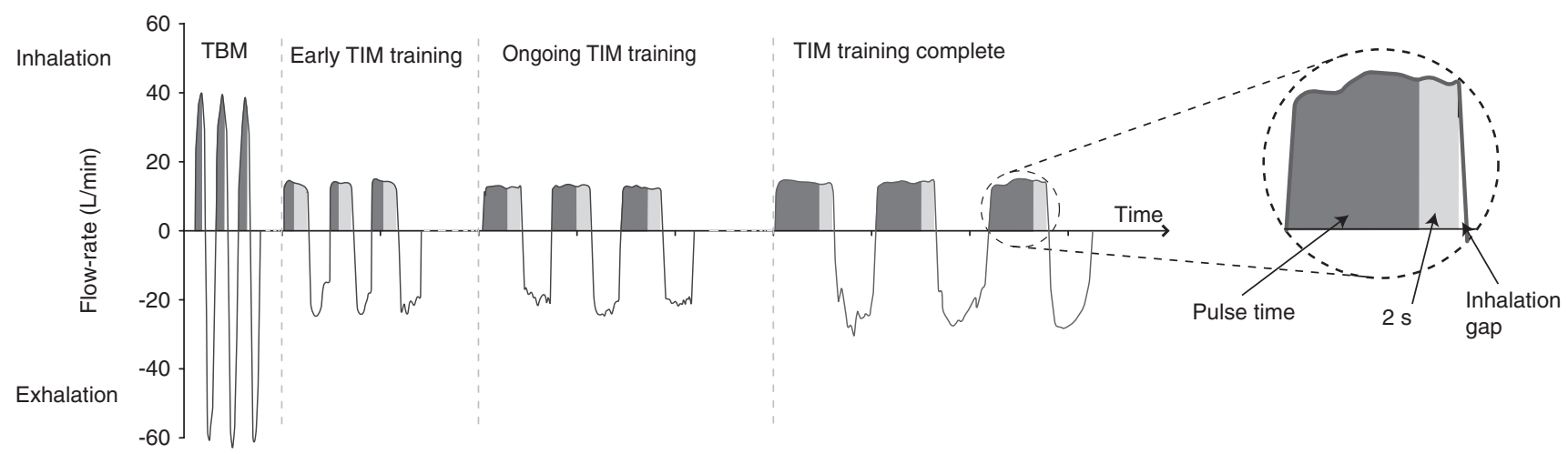

FIG. 2. A graphic presentation of breath patterns for Tidal Breathing Mode (TBM) and Target Inhalation Mode (TIM).

bation of cardiopulmonary disease in the previous 4 weeks or recent hemoptysis were excluded from participation. Patients were instructed to continue all current therapies and medications while participating in the study.

\section{TIM breathing}

The study equipment consisted of a customized I-neb AAD System handset molding containing a flow restrictor, pneumotach, and vibration device connected to a personal computer operating the I-neb AAD software (Philips Respironics; Fig. 1). The flow restrictor limited the inhalation flow rate to $\sim 20 \mathrm{~L} / \mathrm{min}$, and the pneumotach permitted the inhalation flow data to be recorded and provided a means of mechanical connection between device and mouthpiece.

For TIM breathing, patients were instructed to inhale until a vibration was felt through the mouthpiece indicating the Inhalation Target Time (ITT) had been achieved. The gap between the vibration and the end of inspiration was referred to as the Inhalation Gap (IG). The ITT was set to $3 \mathrm{sec}$ for the first breath and increased with each successive breath until the patient's maximal inhalation or the maximum ITT of $9 \mathrm{sec}$ was attained. For subsequent breaths, the ITT was set to oscillate around the maximal inhalation time achievable by the patient. If the patient became unable to achieve maximal ITT, subsequent ITTs were reduced by the software.

For each breath, the computer calculated the pulse time, defined as the time from the beginning of inhalation during which aerosol would have been pulsed. Pulse time was set at $1 \mathrm{sec}$ during the initial breath and, for subsequent breaths, was set to terminate $2 \mathrm{sec}$ before the ITT. Although no medication was delivered, a cumulative pulse time of $50 \mathrm{sec}$ was referred to as a completed treatment, indicated by auditory feedback from the device. Patients completed up to a maximum of eight TIM breathing maneuvers, with a rest period of approximately $10 \mathrm{~min}$ between each, and were permitted to discontinue participation at any time.

\section{Acceptability}

After the initial treatment, the investigator recorded the patients' responses to the following open questions:

1. How easy did you find the instructions to understand?

2. Is there anything that would have helped you understand it?

3. How did you find the length of breath?

4. Was it comfortable?
Following all subsequent treatments (two to eight), the investigator recorded the patients' responses to the following open questions (Table 1):

1. How did you find that?

2. How was the length of breath?

3. Do you feel tired at all?

4. Was the duration of treatment acceptable?

After the final treatment, the patients filled in a questionnaire with the following Likert-style (graded "very easy to "very difficult" for questions 1 and 2, graded "very pleasant" to "very unpleasant" for question 3, and graded "too long" to "too short" for question 4) questions:

1. How easy did you find it to understand what you had to do?

2. Once you had learned what to do, how easy did you find using this nebuliser?

3. What did you think about the vibration that indicated you had breathed in deep enough?

4. How did you find the length of the breath at the end of the study?

\section{Logged data}

Pulse time and inhalation time data were compared to provide an objective measure of whether the patients were able to comply with the TIM breathing maneuver. Peak inhalation flow (PIF) data was sampled for each patient every $10 \mathrm{msec}$ throughout treatment, and was saved to the computer. To compare these parameters, it was necessary to identify individual breaths within the flow data. This was achieved by converting the flow data file (Labview, National Instruments Corporation, Austin, TX, USA) into a file format that could be reproduced on a breathing simulator and then analyzed to distinguish the start and end of each breath. Subtracting breath start time from end time provided the duration of each breath; pulse time was calculated from each pulse's start and end times. The ITT was calculated to be $2 \mathrm{sec}$ longer than the associated pulse time.

The logged data was analyzed to determine the treatment times as well as the number of breaths required to complete each treatment. Treatment time was defined as the time from the initiation of the first inhalation to the termination of the final inhalation. 
Table 1. Results from the Patients' Questionnaires following Treatments 2 through 8

\begin{tabular}{|c|c|c|c|c|c|c|c|}
\hline & 2 & 3 & 4 & 5 & 6 & 7 & 8 \\
\hline Treatment & $\begin{array}{c}n(\%) \\
(n=20)\end{array}$ & $\begin{array}{c}\mathrm{n}(\%) \\
(\mathrm{n}=20)\end{array}$ & $\begin{array}{c}\mathrm{n}(\%) \\
(\mathrm{n}=18)\end{array}$ & $\begin{array}{c}\mathrm{n}(\%) \\
(\mathrm{n}=13)\end{array}$ & $\begin{array}{c}\mathrm{n}(\%) \\
(\mathrm{n}=8)\end{array}$ & $\begin{array}{l}\mathrm{n}(\%) \\
(\mathrm{n}=3)\end{array}$ & $\begin{array}{l}\mathrm{n}(\%) \\
(\mathrm{n}=1)\end{array}$ \\
\hline \multicolumn{8}{|l|}{ How did you find that? } \\
\hline Easy/easier/better/hit more vibrations & $10(50)$ & $1(5)$ & $3(15)$ & $4(20)$ & $1(5)$ & 0 & 0 \\
\hline OK/about the same & $4(20)$ & $6(30)$ & $4(20)$ & $2(10)$ & $2(10)$ & $2(10)$ & 0 \\
\hline Not too bad/not as comfortable & $1(5)$ & $1(5)$ & $2(10)$ & 0 & 0 & 0 & $1(5)$ \\
\hline $\begin{array}{l}\text { Hard/harder/difficult/breaths too long/ } \\
\text { too deep/could not reach vibration }\end{array}$ & $5(25)$ & $12(60)$ & $8(40)$ & $5(25)$ & $4(20)$ & 0 & 0 \\
\hline $\begin{array}{l}\text { Not as hard since stopped trying/ } \\
\text { managed first vibration/early vibrations }\end{array}$ & 0 & 0 & $1(5)$ & $2(10)$ & $1(5)$ & $1(5)$ & 0 \\
\hline \multicolumn{8}{|l|}{ How was the length of breath? } \\
\hline Better & $3(15)$ & 0 & $1(5)$ & $1(5)$ & 0 & 0 & 0 \\
\hline Same/ok/fine/alright & $8(40)$ & $3(15)$ & 0 & $1(5)$ & $1(5)$ & 0 & 0 \\
\hline $\begin{array}{l}\text { On the limit/uncomfortable/max could cope } \\
\text { with/edge of capacity/full lung capacity }\end{array}$ & $3(15)$ & $1(5)$ & $1(5)$ & 0 & 0 & $1(5)$ & 0 \\
\hline Too long/more difficult/harder & $6(30)$ & $15(75)$ & $14(70)$ & $10(50)$ & $6(30)$ & $1(5)$ & 0 \\
\hline (Could) not hit(ting) vibrations & 0 & $1(5)$ & $2(10)$ & $1(5)$ & $1(5)$ & $1(5)$ & $1(5)$ \\
\hline \multicolumn{8}{|l|}{ Did you feel tired at all? } \\
\hline Yes/more tired & $3(15)$ & $5(25)$ & $3(15)$ & $4(20)$ & $2(10)$ & $1(5)$ & 0 \\
\hline A bit/slightly/a little/a bit in the middle & $3(15)$ & $2(10)$ & $2(10)$ & $2(10)$ & $2(10)$ & $1(5)$ & $1(5)$ \\
\hline No/not really & $14(70)$ & $13(65)$ & $13(65)$ & $7(35)$ & $4(20)$ & $1(5)$ & 0 \\
\hline \multicolumn{8}{|l|}{ Was the duration of treatment acceptable? } \\
\hline Very acceptable/yes very/very good & $3(15)$ & 0 & 0 & 0 & 0 & 0 & 0 \\
\hline Yes/fine & $16(80)$ & $20(100)$ & $18(90)$ & $13(65)$ & $8(40)$ & $3(15)$ & $1(5)$ \\
\hline $\mathrm{OK}$ & $1(5)$ & 0 & 0 & 0 & 0 & 0 & 0 \\
\hline
\end{tabular}

\section{Safety}

Although no medication was administered during the study, spirometric measurement of $\mathrm{FEV}_{1}$ and forced vital capacity (FVC) was performed before and after participation in the study as an assessment of safety. Percent of predicted normal $\mathrm{FEV}_{1}$ and FVC were compared to ensure that the effort to comply with the TIM breathing maneuver did not affect lung function. The highest values for each variable were automatically selected by the spirometer from three consecutive attempts. ${ }^{(28)}$ Thus $\mathrm{FEV}_{1}$ and FVC were not necessarily derived from the same attempt. The occurrence and severity of adverse events were recorded from the time informed consent was provided.

\section{Statistics}

A sample size of 20 was considered as being appropriate for this exploratory study. The primary acceptability variables included the patients' responses to questions and their responses to a systematic questionnaire. The secondary acceptability variable was based on an analysis of the logged data to determine the patients' ability to comply with the TIM breathing maneuver. No formal statistical analyses were conducted. Categorical data was summarized descriptively and frequencies were tabulated. Continuous variables were presented using the mean, minimum, and maximum values.

\section{Results}

Patients

A total of 20 patients (nine female) were enrolled and completed the study. Mean age was 27.3 years (range: 18.2-54.2 years). Mean height and weight were $167.6 \mathrm{~cm}$ (range:
$142-183 \mathrm{~cm}$ ) and $61.6 \mathrm{~kg}$ (range: $35-88 \mathrm{~kg}$ ), respectively. No concomitant medication use was required during the study.

The mean and median duty cycles of the patients' breathing patterns in the TIM breathing maneuver were $\sim 0.55$ and $\sim 0.56$ (range: $0.25-0.75$ ). There were no significant changes in mean $\mathrm{FEV}_{1}$ and FVC measured before and after the study, demonstrating that repeated performance of the TIM breathing maneuver did not produce a decrease in pulmonary function. The baseline mean $\mathrm{FEV}_{1}$ was $1.9 \mathrm{~L}$ (range: $0.6-3.2 \mathrm{~L}$; range of predicted normal 26-72\%), and the mean $\mathrm{FEV}_{1}$ at the end of treatments was $1.9 \mathrm{~L}$ (range: 0.7-3.2 L; range of predicted normal $27-74 \%$ ). The baseline mean FVC was $3.0 \mathrm{~L}$ (range: 1.4-5.4 L; range of predicted normal $46-104 \%$ ), and the mean FVC at the end of treatments was 3.0 L (range: $1.5-4.4 \mathrm{~L}$; range of predicted normal 46-90\%). No adverse events were reported during the study.

\section{Acceptability}

According to the responses from the patients recorded by the investigator, 15 patients (75\%) found the TIM breathing maneuver procedure very easy or easy to understand, 3 $(15 \%)$ found it acceptable, and $1(5 \%)$ found it difficult to understand; for one patient $(5 \%)$, no response was recorded. Seven patients $(35 \%)$ required additional instructions.

At the end of the initial treatment, 18 patients (90\%) felt that the instructions were very easy or easy to understand, and $12(60 \%)$ thought the instructions were detailed enough. Most patients $(n=13 ; 65 \%)$ thought that the vibration was pleasant, and half felt that the procedure was comfortable. The majority of patients $(n=17 ; 85 \%)$ noticed the length of their breath changing, and 11 (55\%) would have preferred shorter inhalation times. 


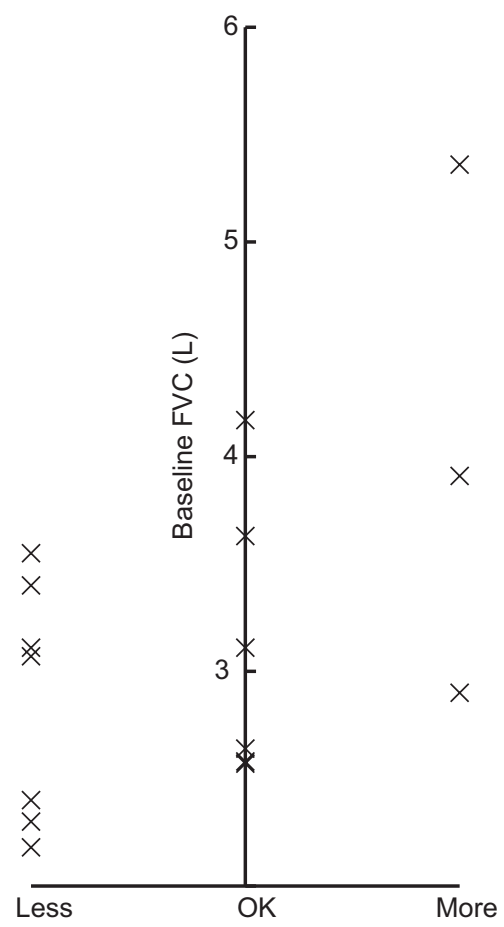

FIG. 3. The figure shows a comparison between the patients' baseline forced vital capacity (FVC) and their opinions on breath length after the first treatment.

Patient responses to open questions following each treatment subsequent to the first were recorded and summarized (Table 1). Half of the patients found the second TIM breathing maneuver to be easier than the first, despite the increased duration. By the end of the third treatment,
12 patients $(60 \%)$ reported that the breathing maneuver had become too difficult, and $16(80 \%)$ felt the duration of the breath to be too long. From the fourth treatment onward, these results coincided with a reduction in the number of patients continuing to additional treatments. Overall, those desiring shorter inhalations were also those with the lowest baseline FVC (Fig. 3). However, despite repeated TIM breathing maneuvers of increasing duration, most patients did not report feeling tired during any given treatment (Table 1). For treatments subsequent to treatment 3 , the number of patients who reported becoming tired or slightly tired approximated the number of patients who did not continue to additional treatment. However, all patients reported that the duration of treatment was acceptable.

At the end of the final treatment, in response to the Likertstyle questions, 18 patients $(90 \%)$ described the breathing maneuver as very easy or easy to understand, and $16(80 \%)$ found the device very easy or easy to use after learning how to use it. Eleven patients (55\%) found the vibration to be very pleasant or pleasant; none found it to be unpleasant. All patients felt that the duration of the inhalation at the end of the study was too long.

\section{Logged data}

The logged data showed that 18 of the 20 patients (90\%) were able to comply with the TIM breathing maneuver. The two patients unable to comply with the TIM breathing maneuver had the lowest baseline FVC values $(1.38$ and $1.71 \mathrm{~L}$; 50 and $46 \%$ of predicted normal) and required the greatest number of breaths to complete the final treatment that they performed (39 and 53, respectively). Overall, the patients' individual mean PIF rates ranged from 13.7 to $21.7 \mathrm{~L} / \mathrm{min}$ (Table 2). The highest individual PIF value was $23.7 \mathrm{~L} / \mathrm{min}$ and the lowest $10.1 \mathrm{~L} / \mathrm{min}$. There was no correlation between

Table 2. The Patients' Peak Inspiratory Flow Rates Measured during Treatments 1 to 8

\begin{tabular}{|c|c|c|c|c|c|c|c|c|c|c|}
\hline \multirow[b]{2}{*}{ Patient } & \multicolumn{8}{|c|}{ Peak inspiratory flow values for treatments 1 to 8} & \multirow[b]{2}{*}{ Mean } & \multirow[b]{2}{*}{$S D$} \\
\hline & 1 & 2 & 3 & 4 & 5 & 6 & 7 & 8 & & \\
\hline 1 & 17.1 & 18.2 & 19.0 & 18.9 & 19.4 & 19.8 & 20.0 & & 18.9 & 1.0 \\
\hline 2 & 16.3 & 14.9 & 16.6 & 16.3 & 15.7 & 14.3 & 13.7 & & 15.4 & 1.1 \\
\hline 3 & 15.1 & 14.1 & 14.0 & 15.0 & 15.0 & 15.6 & 14.8 & 15.8 & 14.9 & 0.6 \\
\hline 4 & 16.5 & 19.9 & 18.0 & 19.4 & 19.1 & 18.2 & & & 18.5 & 1.2 \\
\hline 5 & 17.6 & 13.5 & 13.3 & 13.9 & & & & & 14.5 & 2.0 \\
\hline 6 & 18.5 & 19.4 & 20.1 & 20.0 & 21.1 & & & & 19.8 & 0.9 \\
\hline 7 & 19.3 & 18.9 & 19.2 & 16.7 & 20.2 & 16.9 & & & 18.5 & 1.4 \\
\hline 8 & 22.2 & 14.3 & 18.0 & 16.4 & 12.6 & & & & 16.7 & 3.7 \\
\hline 9 & 21.8 & 22.2 & 20.9 & 19.3 & 19.6 & 21.4 & & & 20.9 & 1.2 \\
\hline 10 & 20.3 & 21.1 & 20.9 & 21.4 & 20.8 & 20.7 & & & 20.9 & 0.4 \\
\hline 11 & 18.8 & 19.8 & 19.6 & 21.7 & & & & & 20.0 & 1.2 \\
\hline 12 & 22.4 & 21.5 & 19.8 & 20.5 & 16.9 & 15.9 & & & 19.5 & 2.6 \\
\hline 13 & 23.4 & 22.3 & 21.4 & 20.6 & 21.0 & & & & 21.7 & 1.1 \\
\hline 14 & 23.7 & 21.9 & 20.8 & 20.3 & 20.6 & & & & 21.4 & 1.4 \\
\hline 15 & 11.7 & 10.1 & 13.3 & 19.5 & & & & & 13.7 & 4.1 \\
\hline 16 & 20.9 & 22.2 & 22.6 & 20.1 & & & & & 21.5 & 1.1 \\
\hline 17 & 16.5 & 14.3 & 13.1 & & & & & & 14.6 & 1.7 \\
\hline 18 & 16.0 & 17.7 & 17.0 & 13.8 & 17.9 & & & & 16.5 & 1.7 \\
\hline 19 & 20.0 & 16.8 & 16.3 & & & & & & 17.7 & 2.0 \\
\hline 20 & 20.5 & 19.4 & 19.9 & 21.8 & & & & & 20.4 & 1.1 \\
\hline Mean & 18.9 & 18.1 & 18.2 & 18.6 & 18.5 & 17.8 & 16.1 & 15.8 & & \\
\hline SD & 3.1 & 3.5 & 2.9 & 2.6 & 2.7 & 2.6 & 3.4 & NA & & \\
\hline
\end{tabular}




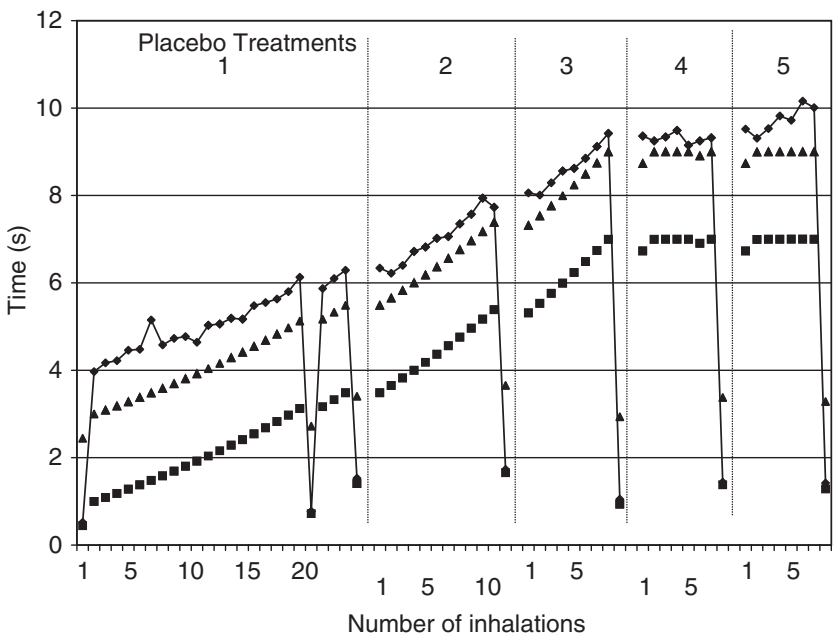

FIG. 4. A graphic presentation of logged data for one of the patients including inhalation time $(\bullet)$, pulse time $(\boldsymbol{\square})$, and Inhalation Target Time $(\boldsymbol{\Delta})$ data. The data were collected over five placebo treatments.

the baseline lung function $\left(\mathrm{FEV}_{1}, \mathrm{FVC}\right)$ and the PIF values. All 18 patients able to comply with the TIM breathing maneuver performed treatments 1,2 , and 3 , until by treatment 8 the number of patients had decreased to only one patient with baseline FVC of $3.45 \mathrm{~L}$ ( $68 \%$ of predicted normal) (Fig. 3). There was no correlation between the baseline lung function $\left(\mathrm{FEV}_{1}, \mathrm{FVC}\right)$ and the number of treatments performed. One patient achieved an inhalation time of $\sim 6 \mathrm{sec}, 3$ patients an inhalation time of $\sim 7 \mathrm{sec}, 3$ patients an inhalation time of $\sim 8 \mathrm{sec}$, and 11 patients achieved an inhalation time of $\sim 9$ sec. A typical plot of the logged data for one of the patients achieving a $\sim 9 \mathrm{sec}$ long inhalation time is shown in
Figure 4. Seventeen of the 20 patients reached a maximum inhalation time plateau during one of the treatments, and of these, 1 reached it during the second treatment, 7 reached it during the third treatment, 8 reached it during the fourth treatment, and 1 reached it during the sixth treatment.

\section{Treatment times}

The mean treatment time for all 20 patients decreased from $288.4 \mathrm{sec}$ during the first treatment to $141.6 \mathrm{sec}$ in the final treatment, representing a $51 \%$ reduction. The mean number of breaths for all patients required to achieve the 50 -sec cumulative pulse time decreased from 30.9 to 13.9 breaths during the first and last treatments, respectively. For the 18 patients able to adapt to the TIM breathing maneuver, the reduction in treatment times and number of breaths was even more pronounced (Fig. 5). The greatest reduction in treatment times occurred within the first three treatmentsfrom 277 to 158 to $136 \mathrm{sec}$-indicating a rapid adjustment to the TIM breathing maneuver. The mean number of breaths for the 18 patients decreased from 27.9 to 10.3 breaths during the first and last treatments, respectively.

\section{Discussion}

The primary objective of the present study was to assess the acceptability of the TIM breathing maneuver in patients with CF during repeated simulated nebulizer treatment with a customized I-neb AAD System device. The results showed that the majority of the patients found the TIM breathing maneuver easy to understand and easy to perform, and that $80 \%$ found the device very easy or easy to use. The logged data showed that $90 \%$ of the patients were able to comply with the TIM breathing maneuver. There were no significant changes in lung function measured before and after the study, showing that repeated performance of the TIM

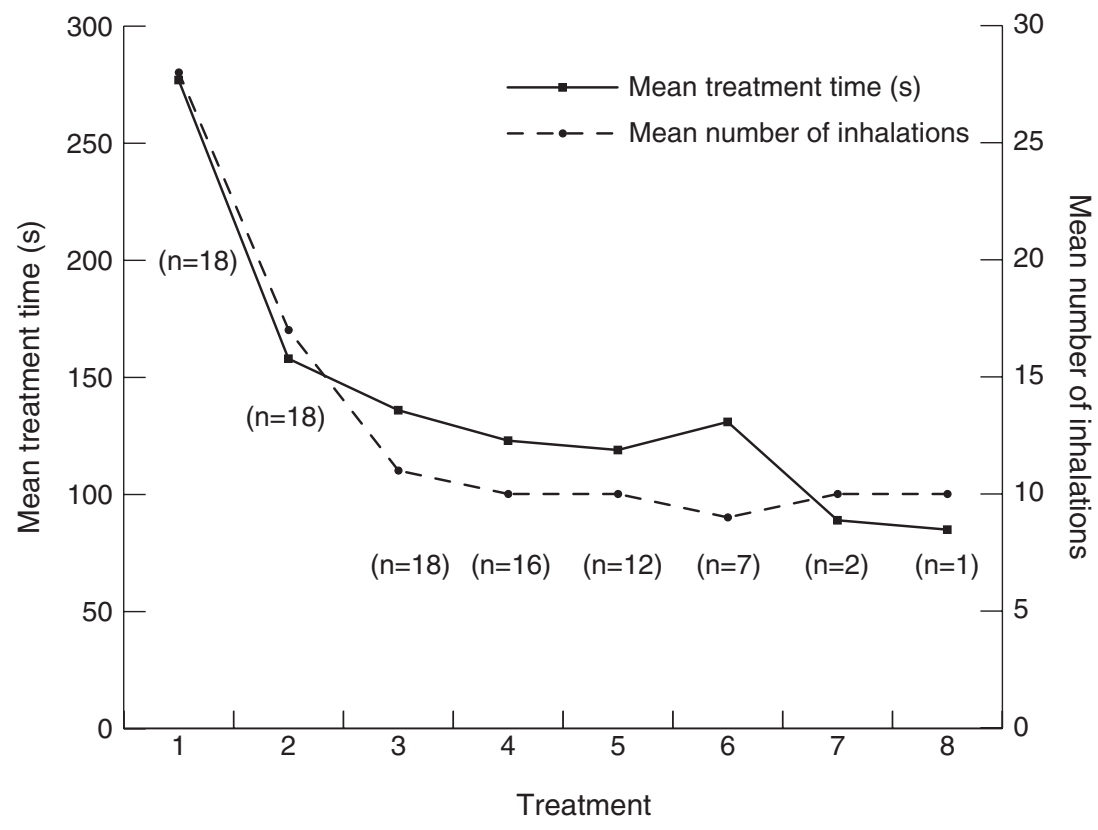

FIG. 5. A graphic presentation of the mean treatment times and the mean number of inhalations during the eight study treatments. The number of inhalations decreased in parallel with the mean treatment time. 
breathing maneuver did not cause a decrease in pulmonary function. No adverse events were reported during the study.

Patients completed up to a maximum of eight TIM breathing maneuvers with a rest period of only $\sim 10 \mathrm{~min}$ between each. Following the first treatment slightly more than half of the patients felt the duration of the breath to be too long although the length of the inhalation was only 3 sec. Those desiring shorter inhalations were also those with the lowest baseline FVC. Surprisingly, $50 \%$ of patients found the second treatment to be easier than the first. By the end of the third treatment, $60 \%$ of patients had an overall negative opinion, and $80 \%$ felt the inhalation to be too long, coinciding with the treatment at which the number of patients continuing to additional treatments began to decrease. Despite this, 18 patients went on to the fourth treatment. The majority of the patients reached a maximum inhalation time plateau during either the third or the fourth treatments.

The majority of the patients able to comply with the TIM breathing maneuver had inhalation times equal to the maximal $9 \mathrm{sec}$, and all ranged from 6 to $9 \mathrm{sec}$. The prolonged inhalation times decreased the average treatment time for all patients by $51 \%$ from 288.4 to $141.6 \mathrm{sec}$ between the first and final treatments, respectively. A slightly greater reduction in treatment times was apparent among the 18 patients who were able to comply with the TIM breathing maneuver. The greatest reduction in the treatment times occurred within the first three treatments, indicating that the patients adjusted relatively easily to the TIM breathing maneuver. Similarly, the number of breaths per treatment decreased $55 \%$ to approximately 14 breaths in the overall population versus $63 \%$ to approximately 10 breaths in compliant patients. Interestingly, the two patients who were unable to comply with the maneuver had the two lowest FVC values prior to the study and required the greatest number of breaths to complete the first treatment. This may indicate that the effectiveness of the TIM breathing maneuver in providing shorter treatment times may be reduced in patients with FVC below approximately $1.75 \mathrm{~L}$. However, additional research is required to support this conclusion.

The equipment used in the present study consisted of a customized I-neb handset molding containing a flow restrictor, a pneumotach, and a vibration device that were connected to a computer operating the software. These functions - a high-resistance mouthpiece, a pressure sensor, a buzzer and vibrations for tactile feedback, and a microprocessor that runs the AAD algorithm-are included in the new I-neb AAD System. ${ }^{(21)}$ Apart from these functions, the device includes an electronic aerosol generation circuit, a piezo element connected to a horn, and a mesh for aerosol generation. ${ }^{(21)}$ When inhaling through the I-neb AAD System, the patient is guided to perform slow and deep inhalations up to $\sim 8 \mathrm{sec}$ with aerosol pulsed up to $7 \mathrm{sec}$, leaving $1 \mathrm{sec}$ for particle deposition in the lungs. The length of the inhalation is individualized, and with each breath the patient is coached to lengthen the inhalation via a vibratory feedback. If the patient cannot reach the ITT once the treatment time has been optimized, the I-neb AAD System gradually shortens the ITT to adapt to the patient's preferred length of inhalation.

\section{Conclusions}

In light of the results of this exploratory study, use of the TIM breathing maneuver during aerosol delivery may pro- vide advantages over aerosol delivery during tidal breathing. In addition to potential benefits such as improved aerosol delivery and lung deposition, the TIM breathing maneuver used in the present study would yield shorter treatment times, which may serve to improve adherence to treatment regimens. ${ }^{(13,15,24,26)}$ Furthermore, the use of pulsed aerosol during inhalation would decrease drug loss to the environment and subsequently caregiver exposure compared with conventional nebulizer systems. ${ }^{(12,14,21,26)} \mathrm{Pa}$ tients' opinions in the present study regarding the I-neb AAD System used were on the whole positive despite the study design that involved repetitive performance of an uncustomary respiratory maneuver with short intervening rest periods. This study indicates that the I-neb AAD System with the TIM breathing maneuver would be an acceptable, user-friendly means of providing inhaled therapy to patients with CF.

\section{Acknowledgments}

The authors acknowledge Nicholas Smith (PS Writing Ltd, Portsmouth, UK) for his assistance with data analysis and graphics, and Kurt Nikander (Philips Respironics, Respiratory Drug Delivery, Parsippany, NJ) for guidance and input on the manuscript. The study was conducted by the Physiotherapy Department, Royal Brompton Hospital in cooperation with Philips Respironics, Respiratory Drug Delivery (UK) Ltd, Chichester, UK. The study was sponsored by Philips Respironics.

\section{Author Disclosure Statement}

The authors declare that no competing financial interests exist. John Denyer is an employee of Philips Respironics, and Ivan Prince was an employee of Philips Respironics during the study.

\section{References}

1. Lewis PA: The epidemiology of cystic fibrosis. In ME Hodson, and DM Geddes (eds). Cystic Fibrosis. Chapman and Hall, London; pp. 1-13, 1995.

2. Sheppard MN: The pathology of cystic fibrosis. In ME Hodson, and DM Geddes (eds). Cystic Fibrosis. Chapman and Hall, London; pp, 131-149, 1995.

3. Geller DE: Choosing a nebulizer for cystic fibrosis applications. Curr Opin Pulm Med. 1997;3:414-419.

4. Geller DE, Eigen H, Fiel SB, Clark A, Lamarre AP, Johnson CA, and Konstan MW: Effect of smaller droplet size of dornase alfa on lung function in mild cystic fibrosis. Pediatr Pulmonol. 1998;25:83-87.

5. Le Brun PPH, de Boer AH, Gjaltema D, Hagedoorn P, Heijerman HGM, and Frijlink HW: Inhalation of tobramycin in cystic fibrosis. Part 1: the choice of a nebulizer. Int J Pharm. 1999;189:205-214.

6. Ramsey BW, Pepe MS, Quan JM, Otto KL, Montgomery AB, Williams-Warren J, Vasiljev-KM, Borowitz D, Bowman CM, Marshall BC, Marshall S, and Smith AL: Intermittent administration of inhaled tobramycin in patients with cystic fibrosis. N Engl J Med. 1999;340:23-30.

7. Katz SL, Ho SL, and Coates AL: Nebulizer choice for inhaled colistin treatment in cystic fibrosis. Chest. 2001;19:250-255.

8. Moss RB: Administration of aerosolized antibiotics in cystic fibrosis patients. Chest. 2001;120:107S-113S. 
9. Garcia-Contreras L, and Hickey AJ: Pharmaceutical and biotechnological aerosols for cystic fibrosis therapy. Adv Drug Deliv Rev. 2002;54:1491-1504.

10. Ryan G, Mukhopadhyay S, and Singh M: Nebulised antipseudomonal antibiotics for cystic fibrosis. The Cochrane Database of Systematic Reviews. 2003; Issue 3. Art. No.: CD001021. DOI: 10.1002/14651858.CD001021.

11. Hagerman JK, Hancock KE, and Klepser ME: Aerosolised antibiotics: a critical appraisal for their use. Expert Opin Drug Deliv. 2006.3:71-86.

12. Touw DJ, Brimicombe RW, Hodson ME, Heijerman HGM, and Bakker W: Inhalation of antibiotics in cystic fibrosis. Eur Respir J. 1995;8:1594-1604.

13. Conway SP, Pond MN, Hamnett T, and Watson A: Compliance with treatment in adult patients with cystic fibrosis. Thorax. 1996;51:29-33.

14. Wilson AM, Nikander K, and Brown PH: Drug device matching. Eur Respir Rev. 2000;10:76:558-566.

15. Hunter V: The daily grind and how to stay sane as a mother of two children with cystic fibrosis. J R Soc Med. 2003; 96(Suppl 43):51-56.

16. Nikander K. Drug delivery systems. J Aerosol Med. 1994; 7(Suppl 1):S19-S24.

17. Mukhopadhyay S, Staddon GE, Eastman C, Palmer M, Rhys Davies E, and Carswell F: The quantitative distribution of nebulized antibiotic in the lung in cystic fibrosis. Respir Med. 1994;194;88:203-211.

18. Saari SM, Vidgren MT, Koskinen MO, Turjanmaa VMH, Waldrep JC, and Nieminen MM: Regional lung deposition and clearance of ${ }^{99 \mathrm{~m}}$ Tc-labeled beclomethasone-DLPC liposomes in mild and severe asthma. Chest. 1998;113: 1573-1579.

19. Nikander K: Adaptive aerosol delivery: the principles. Eur Respir Rev. 1997;7:51:385-387.

20. Denyer J: Adaptive aerosol delivery in practice. Eur Respir Rev. 1997.7:388-389.

21. Denyer J: Nikander K, and Smith NJ: Adaptive Aerosol Delivery $\left(\mathrm{AAD}^{\circledR}\right)$ technology. Expert Opin Drug Deliv. 2004a;1:165-176.

22. Byrne NM, Keavey PM, Perry JD, Gould FK, and Spencer DA: Comparison of lung deposition of colomycin using the HaloLite and the Pari LC Plus nebulisers in patients with cystic fibrosis. Arch Dis Child. 2003;88:715-718.
23. Kastelik JA, Wright GA, Aziz I, Davies M, Avery GR, Paddon AJ, Howey S, and Morice AH: A widely available method for the assessment of aerosol delivery in cystic fibrosis. Pulm Pharmacol Ther. 2002;15:513-519.

24. Smaldone GC: Assessing new technologies: patient-device interactions and deposition. Respir Care. 2005;50:1151-1158.

25. Prince I, Seamark D, Pinnuck M, Hinch S, Denyer J, and Conway J: Evaluation of a guided breathing manoeuvre for nebulised inhaled therapy. In Byron PR, Dalby RN, Peart J, Suman JD, and Farr SJ (eds). Respiratory Drug Delivery IX. Virginia Commonwealth University, Richmond, VA; pp. 315-318, 2004.

26. Nikander K, Prince I, Coughlin SR, Warren S, and Taylor G: Lung deposition of 99 mTc-DTPA delivered with I-neb ${ }^{\circledR}$ Adaptive Aerosol Delivery $\left(\mathrm{AAD}^{\circledR}\right)$ system. Eur Respir J. 2007;545s.

27. Quanjer PH, Tammeling GJ, Cotes J, Pedersen R, Peslin R, and Yernault J-C: Lung volumes and forced ventilatory flows: Report of Working Party, Standardization of lung function tests, European Community for Steel and Coal; Official statement of the European Respiratory Society. Eur Respir J. 1993;6(Suppl 16):5-40.

28. American Thoracic Society: Snowbird Workshop on standardization of spirometry. Am Rev Respir Dis. 1979;119: 831-838.

Received on June 3, 2009

in final form, November 30, 2009

Reviewed by: William Bennett

Address correspondence to: John Denyer, B.Sc. Philips Respironics Respiratory Drug Delivery Chichester Business Park City Fields Way, Tangmere Chichester, West Sussex, UK, PO22 2FT E-mail: john.denyer@philips.com 